\title{
A Comparison of Student Grades, Floral Design Laboratory Skill Scores, and Course Satisfaction of Traditional and Online Sections of a University Floral Design Course
}

\author{
S.R. Henss ${ }^{1}$, J.M. Zajicek ${ }^{2}$, and R.D. Lineberger ${ }^{2}$
}

AdDitionAL INDEX wORDs. web-based course

Summary. Performance of college-level floral design students was compared using a sample of 140 students from Texas A\&M University. The experimental group was enrolled in the online version of the course, while the control group was enrolled in the traditional version of the course. Students in both groups were asked to fill out surveys at the beginning and end of the semester. In addition, student floral designs were evaluated at the beginning and end of the semester, and student grades were compared at the end of the semester. No statistically significant differences were noted in terms of student course satisfaction. However, differences were noted in course grades, with those enrolled in the traditional section of the course outperforming those in the online section. Overall, the students in both sections of the course did well in terms of grades, floral design skill scores, and course satisfaction. Results indicated that certain student characteristics may be indicators for student success in online courses.

A lthough many people may think of it as a new technology, the concept of distance learning has been around since at least the 1870s, when the first college correspondence courses were offered (McVay, 2000). Traditionally, distance learning served the needs of those who could not receive an education otherwise, including people whom were placebound, whether due to illness, incarceration, family duties, or whom were geographically isolated from institutions of higher education. Now a shift is occurring where distance learning is not only an essential option for these populations, but more often, merely a convenient option for a broader range of individuals (Primary Research Group, Inc., 1997). The Internet has become the fastest-growing medium for use in American educational distance learning endeavors (McVay, 2000).

As online learning has exploded onto the academic scene, so have statistics to back up the effectiveness of these new methods. Weldon's study (1999) of an online statistics course found that the students in the tradi-

${ }^{1}$ Graduate assistant, Department of Horticultural Sciences, Texas A\&M University, College Station, TX 77842-2133.

${ }^{2}$ Professor, Department of Horticultural Sciences, Texas A\&M University, College Station, TX 77842-2133. tional and online sections performed in a comparable manner on the course exams. However, he also determined that when given a choice, only $20 \%$ of the students would choose the online course. Nonetheless, he felt that the online course did fill an important need for students who lived far away or had schedule conflicts (Weldon, 1999).

A study of computer science majors enrolled in a computer science course found that the online students and traditional students performed equally well in the course (Buerck et al., 2003). Aragon et al. (2002) also found that students in online and traditional versions of a graduate instructional design course performed equally well, despite differences in learning styles. Carey's (2001) study of an undergraduate management information systems course showed no statistically significant differences in student grades. These studies seem to indicate that as long as an online course is designed well, students should be able to experience success at least equivalent to that which they would in a traditional course.

However, there is also a growing body of literature claiming there are, indeed, significant differences between the two types of course offerings (Russell, 2002). Online students were found to perform worse than traditional students in studies involving microeconomics and English courses. However, most studies cited reported online students performing better than their traditional counterparts in physics, psychology, English, and economics (Russell, 2002). It is interesting to note that even in the same subject, in this case English, outcomes were not always similar.

In the midst of this evolution of distance learning, it is important to stop and consider the advantages, disadvantages, and opinions regarding the techniques in addition to the effectiveness of the courses. One general advantage of a distance course, including online courses, is the flexibility for the student. Students have the ability to take courses they might otherwise miss due to the inability to be on the campus where the course is offered (McVay, 2000).

A particular advantage with online courses comes from using the computer as an instructional tool. As computer technology advances, access increases as more and more people are linked together (Willis, 1993). Additionally, students can access the material at any time of day, and have access to the course materials at any time during the course, rather than enduring "fixed delivery" of the lessons (Nguyen and Kira, 2000). Another advantage students report is that the online environment allows them to feel anonymous, and therefore freer to ask questions (Vonderwell, 2003).

However, this freedom can also be a disadvantage for students in distance learning situations. Poor time management and neglect of coursework can result when students are unprepared for the self-direction and self-motivation inherently required in distance courses (Cheurprakobkit et al., 2002; McVay, 2000). Students often view online courses as merely more convenient and easier. They do not understand that an online course demands more from them because it is less structured, and that the instructor is not as visible as in a traditional class (Palloff and Pratt, 2002).

Online courses that have been evaluated in the past were "lecture only" or "concrete concept" distance learning courses. In contrast, the course evaluated in this research study, a floral design course, attempts to teach students a visual art form. Few, if any, 
studies have tried to evaluate the effectiveness of teaching an art course via the computer and Internet. Often, people have a hard time seeing how art and technology fit together on many levels (Narey, 2003). The goal of this study was to determine if a visual art university-level floral design course for credit could be taught as effectively online when compared to the traditional lecture/laboratory method of teaching the same course.

\section{Materials and methods}

Population. The sample for this study consisted of 93 students enrolled in a traditional section of a floral design course, and 73 students enrolled in an online section of the same floral design course. Most students were "traditional" undergraduates; that is, students who physically attended the majority of their classes on campus and were enrolled in a regular, non-distance four to 5-year degree program. The students in the online section of the course were mostly students who simply could not get in to the traditional sections or could not fit the traditional sections into their schedules, as opposed to students who were actually physically unable to come to campus to attend the traditional section.

Courses. All students in both groups (traditional section and online section) participated in the course as they normally would in any given semester. The traditional section of the course lecture met for $1 \mathrm{~h}$ twice weekly for a slideshow and discussion of material. The online section of the course was offered on a password protected website for online students to access the same slideshow and notes lecture material anytime and learn material at their own pace.

For the laboratory portion of the course, students in the traditional section of the course met once weekly for 2 h. Four different graduate assistants taught five sections of the laboratory. Weekly floral designs were demonstrated by the graduate assistant and then constructed by the students in the laboratory. The graduate assistant for each laboratory section monitored the students as they performed the activity. The students in the online section of the course had a separate laboratory in which they completed weekly laboratory floral design assignments during given times including from 0900 to 1400 Hr on Tuesdays and Wednesdays, or 1300 to 1600 HR on Thursdays. Students in the online section laboratory watched a short video demonstration of the floral design, as well as still slides on a computer before completing the laboratory assignment. Graduate assistants were present during these laboratory periods to assign grades on the assignment, but not to help the students complete their designs.

Procedure and InstrumentaTION. At the beginning of the semester, students who agreed to participate in the study were asked to fill out the demographic form designed by the principal investigator. Demographic information was collected including age, gender, ethnicity, major, student classification, grade point averages, SAT scores, previous experiences with floral design and web-based courses, modes of Internet access, connection speeds and initial opinion of the course.

Additionally, two surveys were administered. The first was the "student self-evaluation checklist" (McVay, 2000), which was designed to help determine whether students were suited to the distance learning environment. This survey was given only to the students enrolled in the web-based section of the course. The student selfevaluation checklist consisted of 13 statements with a Likert-type response scale that included answers based on the tendencies to do certain activities. Answers included the following: $1=$ rarely, 2 = sometimes, $3=$ most of the time, and $4=$ all of the time. The coded responses were averaged to produce a distance preparedness score average ranging from 1 (completely unprepared) to 4 (well-prepared) for each student in the web-based course.

The "survey of student technology experience" (McVay, 2000) was designed to determine students' level of technology experience and was administered to all students enrolled in the course. The survey included a series of 40 statements with "yes" or "no" responses. "Yes" responses were coded as 1 and "no" responses were coded as 2 . These numbers were averaged to provide each student with a technology experience score average ranging from 1 (completely familiar with the technology) to 2 (completely unfamiliar with the technology).

Lecture grades were determined by the professor of the course and were based on three exams and three quizzes.
A final exam was also given, although students with A averages were excused from the final. Laboratory grades were based on weekly quizzes, a midterm quiz, and a final quiz. The other portion of the laboratory grade was based on weekly floral design completion grades, as well as a skill-based final design grade.

Student-created designs were evaluated during the first and last laboratory sessions using a modified version of MacAlpine's (2002) criteria, which was based on the Pi Alpha Xi National Honor Society for Floriculture, Landscape Horticulture, and Ornamental Horticulture judging standards. Designs were rated as good, fair, or poor in each of the following categories: suitability/conformity, balance/proportion, focal area, line/ rhythm, and mechanics. Later, values were assigned as follows, with an average being calculated to give the total design score: good $=3$, fair $=2$, and poor $=1$.

During the last regular week of classes, students in both groups were asked to evaluate the course during their laboratory time using a modified version of the course evaluation instrument (CEI) developed for use by the University of South Australia (University of South Australia, 2002). The CEI was designed to gauge students' reactions to and opinions about various facets of a course, such as curriculum design, assessment, and support. The survey was modified to fit the needs of the study by using only those sections and questions relevant for the course. The survey statements were answered by students on a Likert-type scale, with the following choices offered: 1 = strongly disagree, 2 = disagree, $3=$ neutral, 4 = agree, and 5 = strongly agree. The coded responses were averaged to produce a course evaluation score average ranging from l (very dissatisfied) to 5 (very satisfied) for each student.

Data Analysis. The initial surveys, design scores, and course evaluations were coded, and numeric values assigned for comparison purposes. Data were entered into a Excel (Microsoft Corp., Redmond, Wash.) spreadsheet, and analyzed using SPSS (10.1 for Windows; SPSS, Chicago). A majority of the data did not meet one or more of the four assumptions needed to use parametric tests, including normality, homogeneity of variance, interval scale, 
and independence (Field, 2000). For this reason, non-parametric tests were used. The Mann-Whitney U test was used to compare means when only two groups existed, and the Kruskal-Wallis test was used when there were more than two groups being compared. The Wilcoxon signed-rank test was used when the scores to be compared came from the same subjects. Spearman's rho correlations were conducted to determine relationships between variables. The critical probability value for all tests was set a priori at 0.05 .

\section{Results and discussion}

Students were similarly demographically distributed within the traditional section of the floral design course and the web-based course in the way they responded to questions concerning gender, grade classification, age, ethnicity, floral design experience and web-based class experience (Table 1). A Mann-Whitney U test was used to compare student grade point averages, SAT scores, and ages to ensure that the web-based class of students and the traditional class of students were similar. No statistically significant scholastic or age differences were apparent in the comparisons (Table 2).

Grade COMPARISON. In order to compare student academic performance in the online and traditional section of the floral design course, course grades were compared between the two groups. Grades were divided into three categories: lecture points, laboratory points, and final grade average. Mann-Whitney U tests were run on all three measures (Table 3 ). There were statistically significant differences in each case, with students in the traditional section outperforming students in the online section in lecture points, laboratory points, and overall course grade by percentage. These results are similar to a minority of literature cited by Russell (2002) showing statistically significant differences in favor of students enrolled in traditional sections of courses in terms of course performance.

Tests were also run to determine whether various other factors had an effect on grades. There were no statistically significant differences noted on final grades based on previous experience in an online course, previous floral design experience, ethnicity, student classification, where students accessed the Internet, or their connection speed.

Table 1. Demographic comparisons of gender, grade classification, age, ethnicity, floral design experience, and web-based class experience in the study of students enrolled in a traditional section and an online section of a floral design course.

\begin{tabular}{|c|c|c|c|c|}
\hline \multirow[b]{2}{*}{ Measure } & \multirow[b]{2}{*}{ Section } & \multirow[b]{2}{*}{ Category } & \multicolumn{2}{|c|}{ Students } \\
\hline & & & (no.) & $(\%)$ \\
\hline \multirow[t]{4}{*}{ Gender } & \multirow[t]{2}{*}{ Traditional } & Male & 14 & 18.7 \\
\hline & & Female & 61 & 81.3 \\
\hline & \multirow[t]{2}{*}{ Web } & Male & 18 & 27.7 \\
\hline & & Female & 47 & 72.3 \\
\hline \multirow[t]{8}{*}{ Grade classification } & \multirow[t]{4}{*}{ Traditional } & Freshman & 9 & 12.0 \\
\hline & & Sophomore & 13 & 17.3 \\
\hline & & Junior & 18 & 24.0 \\
\hline & & Senior & 35 & 46.7 \\
\hline & \multirow[t]{4}{*}{ Web } & Freshman & 4 & 6.2 \\
\hline & & Sophomore & 12 & 18.5 \\
\hline & & Junior & 18 & 27.7 \\
\hline & & Senior & 31 & 47.7 \\
\hline \multirow[t]{17}{*}{ Age } & \multirow[t]{8}{*}{ Traditional } & 18 years & 6 & 8.0 \\
\hline & & 19 years & 11 & 14.7 \\
\hline & & 20 years & 15 & 20.0 \\
\hline & & 21 years & 27 & 36.0 \\
\hline & & 22 years & 10 & 13.3 \\
\hline & & 23 years & 3 & 4.0 \\
\hline & & 24 years & 1 & 1.3 \\
\hline & & 25 years & 1 & 1.3 \\
\hline & \multirow[t]{9}{*}{ Web } & 18 years & 4 & 6.2 \\
\hline & & 19 years & 8 & 12.3 \\
\hline & & 20 years & 12 & 18.5 \\
\hline & & 21 years & 16 & 24.6 \\
\hline & & 22 years & 17 & 26.2 \\
\hline & & 23 years & 5 & 7.7 \\
\hline & & 27 years & 1 & 1.5 \\
\hline & & 29 years & 1 & 1.5 \\
\hline & & 33 years & 1 & 1.5 \\
\hline \multirow[t]{10}{*}{ Ethnicity } & \multirow[t]{5}{*}{ Traditional } & Caucasian & 70 & 93.3 \\
\hline & & African-American & 1 & 1.3 \\
\hline & & Hispanic & 3 & 4.0 \\
\hline & & Asian-American & 0 & 0.0 \\
\hline & & Other & 1 & 1.3 \\
\hline & \multirow[t]{5}{*}{ Web } & Caucasian & 57 & 87.7 \\
\hline & & African-American & 0 & 0.0 \\
\hline & & Hispanic & 5 & 7.7 \\
\hline & & Asian-American & 1 & 1.5 \\
\hline & & Other & 2 & 3.1 \\
\hline \multirow[t]{4}{*}{ Floral design experience } & \multirow[t]{2}{*}{ Traditional } & Yes & 9 & 12.0 \\
\hline & & No & 66 & 88.0 \\
\hline & \multirow[t]{2}{*}{ Web } & Yes & 7 & 10.8 \\
\hline & & No & 58 & 89.2 \\
\hline \multirow[t]{4}{*}{ Prior web-based class } & \multirow[t]{2}{*}{ Traditional } & Yes & 13 & 17.3 \\
\hline & & No & 62 & 82.7 \\
\hline & \multirow[t]{2}{*}{ Web } & Yes & 14 & 21.5 \\
\hline & & No & 51 & 78.5 \\
\hline
\end{tabular}

However, three factors did appear to be related to grades: gender, initial pre-course statement, and post-course statement.

A Mann-Whitney U test comparing males and females across both sections indicated that females had statistically significantly higher grades (Table 4). Overall, females in the course scored an average of 45 points higher than males. The data were then broken down into gender comparisons within both the online and traditionally taught sections (Table 5 ). Since females out- 
Table 2. A Mann-Whitney U test comparison of students' grade point averages, SAT scores, and ages in the study of students enrolled in a traditional section and an online section of a floral design course.

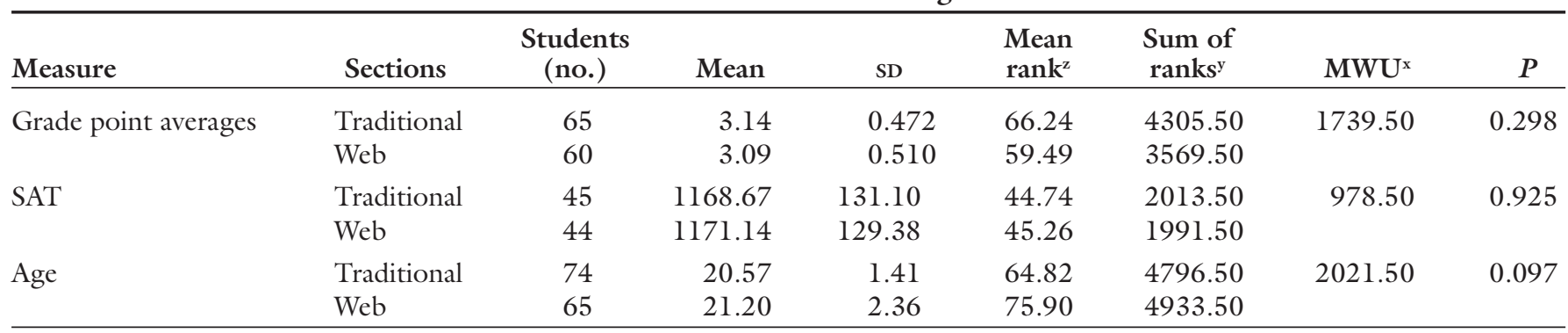

${ }^{2}$ Mean of ranks of data; in a Mann-Whitney test, data are analyzed by ranking the means of the variables of interest.

y

${ }^{x}$ Mann-Whitney U test statistic.

Table 3. A Mann-Whitney U test comparison of students' lecture points, laboratory points and overall course average in the study of students enrolled in a traditional section and an online section of a floral design course.

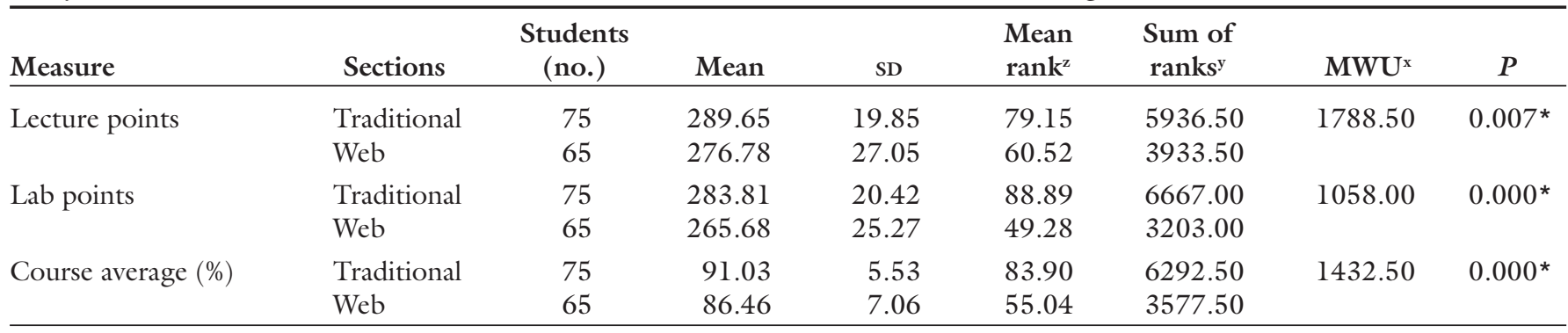

${ }^{2}$ Mean of ranks of data; in a Mann-Whitney test, data are analyzed by ranking the means of the variables of interest.

'Sum of the ranked data (number of cases $\times$ mean rank).

${ }^{x}$ Mann-Whitney U test statistic.

* Significant at $P<0.05$.

Table 4. A Mann-Whitney U test comparison of male and female students' lecture points, laboratory points, and overall course average in both the online and traditional sections of floral design in the study of students enrolled in a traditional section and an online section of a floral design course.

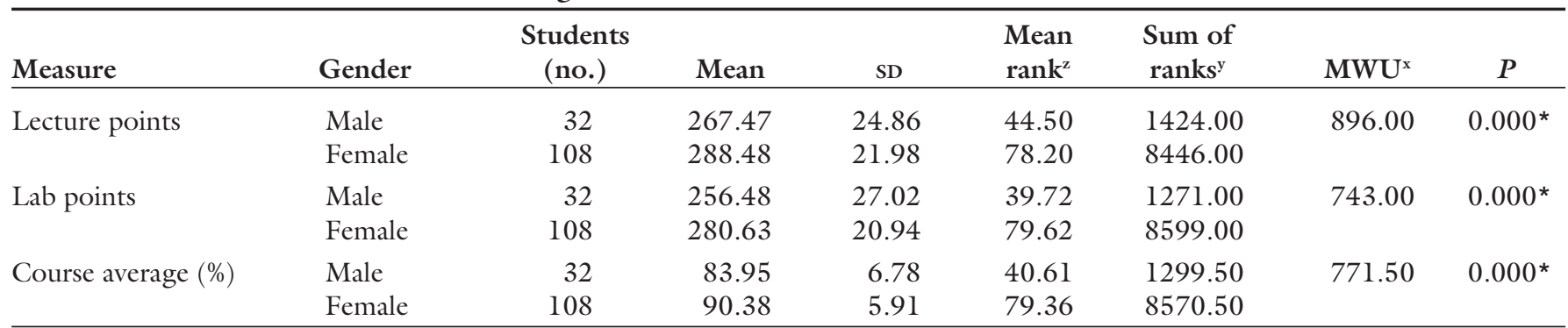

${ }^{2}$ Mean of ranks of data; in a Mann-Whitney test, data are analyzed by ranking the means of the variables of interest.

y Sum of the ranked data (number of cases $\times$ mean rank).

${ }^{x}$ Mann-Whitney U test statistic.

* Significant at $P<0.05$.

performed the males academically in both sections, no course offering technique appeared to be more favorable for either gender. When interpreting these findings, it should also be noted that demographic data collected at the start of the semester indicated that females had higher grade point averages compared to males, which Hong (2002) cites as an indicator of more success, as well as more preparedness for a distance course.

Grades were also compared based on students' feelings about whether the section in which they were enrolled was the section they originally preferred to be enrolled. This factor was measured using students' pre- and post-course statements (Table 6). There was a statistically significant difference in grades in both cases. Though the nonparametric Kruskal-Wallis test does not reveal exactly where the significant difference occurred, the averages revealed that students who stated that they were enrolled in the section they preferred (online vs. traditional) had higher average grades when compared to those who were neutral concerning course options, or not enrolled in the course they wanted. Thus, section preference appears to play a logical role, in that a student will do better if they are in the type of section they prefer.

In addition to mean comparisons, Spearman's rho correlations were also conducted with grade data (Table 7). Gender was correlated to final grades, with females having higher grades. This supported the previous findings from the Mann-Whitney $U$ tests. In addition, students who scored higher on the distance preparedness survey and students who reported higher GPAs had higher final grades in the class. 
Table 5. A Mann-Whitney $U$ test comparison of males and females enrolled in the traditional and online sections of the floral design course on lecture points, laboratory points and overall course average in the study of students enrolled in a traditional section and an online section of a floral design course.

\begin{tabular}{llcrrrrrr}
\hline Measure & Gender & $\begin{array}{c}\text { Students } \\
\text { (no.) }\end{array}$ & Mean & SD & $\begin{array}{c}\text { Mean } \\
\text { rank }^{\mathbf{z}}\end{array}$ & $\begin{array}{r}\text { Sum of } \\
\text { ranks }^{\text {y }}\end{array}$ & MWU $^{\text {* }}$ & \multicolumn{1}{c}{$\boldsymbol{P}$} \\
\hline Traditional section & & & & & & & & \\
Lecture points & Male & 14 & 279.79 & 19.71 & 27.61 & 386.50 & 281.50 & $0.048^{*}$ \\
& Female & 61 & 291.92 & 19.34 & 40.39 & 2463.50 & & \\
Lab points & Male & 14 & 268.54 & 23.64 & 19.50 & 273.00 & 168.00 & $0.000^{*}$ \\
& Female & 61 & 287.31 & 18.07 & 42.25 & 2577.00 & & \\
Course average (\%) & Male & 14 & 88.03 & 5.17 & 23.89 & 334.50 & 229.50 & $0.007^{*}$ \\
& Female & 61 & 91.72 & 5.42 & 41.24 & 2515.50 & & \\
Online section & & & & & & & & \\
Lecture points & Male & 18 & 257.89 & 24.64 & 19.94 & 359.00 & 188.00 & $0.001^{*}$ \\
& Female & 47 & 284.02 & 24.51 & 38.00 & 1786.00 & & \\
Lab points & Male & 18 & 247.11 & 26.29 & 19.72 & 355.00 & 184.00 & $0.000^{*}$ \\
& Female & 47 & 271.97 & 21.40 & 38.09 & 1790.00 & & \\
Course average (\%) & Male & 18 & 80.78 & 6.24 & 17.47 & 314.50 & 143.50 & $0.000^{*}$ \\
& Female & 47 & 88.64 & 6.13 & 38.95 & 1830.50 & & \\
\hline
\end{tabular}

${ }^{2}$ Mean of ranks of data; in a Mann-Whitney test, data are analyzed by ranking the means of the variables of interest.

y Sum of the ranked data (number of cases $\times$ mean rank).

'Mann-Whitney U test statistic.

* Significant at $P<0.05$.

Table 6. A Kruskal-Wallis test comparison of overall course grades, based on students' pre- and post-course preference statements ${ }^{y}$, in the study of students enrolled in a traditional section and an online section of a floral design course.

\begin{tabular}{lcccccccc}
\hline Measure & Statement & $\begin{array}{c}\text { Students } \\
\text { (no.) }\end{array}$ & $\begin{array}{c}\text { Course } \\
\text { average }\end{array}$ & SD & $\begin{array}{c}\text { Mean } \\
\text { rank }^{z}\end{array}$ & df & Chi-square & $P$ \\
\hline Pre-course & 1 & 67 & 90.91 & 5.69 & 82.04 & 3 & 11.95 & $0.008^{*}$ \\
& 2 & 20 & 88.49 & 5.36 & 62.47 & & & \\
Post-course & 3 & 32 & 85.93 & 8.39 & 55.61 & & & \\
& 5 & 20 & 87.95 & 5.75 & 60.22 & & & $0.002^{*}$ \\
& 1 & 56 & 91.26 & 5.39 & 76.25 & 4 & & \\
& 2 & 35 & 88.30 & 6.14 & 56.94 & & & \\
& 3 & 12 & 87.24 & 6.40 & 51.21 & & & \\
& 4 & 3 & 88.22 & 11.99 & 69.63 & & & \\
& 5 & 19 & 83.81 & 8.55 & 41.55 & & &
\end{tabular}

"Statements were coded as follows: pre-course - I = "I got into the traditional course, which was what I wanted," 2 = "I got into the web-based course, which was what I wanted," 3 = "It did not matter to me whether I got in the traditional or web-based course," 4 = "I got into the traditional course, but I wanted to be in the web-based course," 5 = "I got into the web-based course, but I wanted to be in the traditional course" post-course - I = "I was in the traditional course, and I am glad I was (rather than the web-based course)," 2 = "I was in the web-based course, and I am glad I was (rather than the traditional course)," $3=$ "The type of course (traditional or web-based) I was in did not make a difference to me," 4 = "I was in the traditional course, but I really wish I had been in the web-based course," $5=$ "I was in the web-based course, but I really wish I had been in the traditional course."

"Mean of ranks of data; in a Kruskal-Wallis test, data are analyzed by ranking the means of the variables of interest.

* Significant at $P<0.05$.

No statistically significant correlations were found between final grades and the technology experience scores or CEI scores (Table 7).

COURSE SATISFACTION. In order to compare student course satisfaction in the online and traditional sections, a Mann-Whitney U test was run comparing student CEI scores between the two sections (Table 8). No statistically significant differences were found between the CEI scores. Both sections reported average CEI
Table 7. Spearman's rho correlations of gender, distance preparedness test scores, grade point average, technology experience scores, and course evaluation scores to student course grades in the study of students enrolled in a traditional section and an online section of a floral design course.

\begin{tabular}{lccc}
\hline Measure & Students (no.) & $\begin{array}{c}\text { Correlation to } \\
\text { course grade }\end{array}$ & $P$ \\
\hline Gender & 140 & 0.403 & $0.000^{*}$ \\
Distance preparedness test score & 65 & 0.322 & $0.009^{*}$ \\
Grade point average & 125 & 0.520 & $0.000^{*}$ \\
Technology experience score & 140 & 0.082 & 0.333 \\
Course evaluation score & 125 & -0.088 & 0.346 \\
\hline
\end{tabular}

*Significant at $P<0.05$. 
Table 8. A Mann-Whitney U test comparison of students' course evaluation (CEI) scores ${ }^{z}$ in the study of students enrolled in a traditional section and an online section of a floral design course.

\begin{tabular}{lccccccc}
\hline Course & $\begin{array}{c}\text { Students } \\
\text { (no.) }\end{array}$ & Mean $^{\mathrm{z}}$ & SD & $\begin{array}{c}\text { Mean } \\
\text { rank }^{\mathrm{y}}\end{array}$ & $\begin{array}{c}\text { Sum } \\
\text { of ranks }^{\mathrm{x}}\end{array}$ & MWU $^{\mathbf{w}}$ & $\boldsymbol{P}$ \\
\hline Traditional & 68 & 4.33 & 0.436 & 66.25 & 4505.00 & 2125.00 & 0.938 \\
Online & 63 & 4.26 & 0.623 & 35.73 & 4141.00 & &
\end{tabular}

${ }^{\mathrm{z}}$ Means can range from 1 (very unsatisfied) to 5 (very satisfied).

${ }^{y}$ Mean of ranks of data; in a Mann-Whitney test, data are analyzed by ranking the means of the variables of interest.

${ }^{x}$ Sum of the ranked data (number of cases $\times$ mean rank)

"Mann-Whitney U test statistic.

Table 9. A chi-square comparison of course satisfaction, as determined by mean course evaluation scores, based on post-course statements for students enrolled in both the traditional and online course sections in the study of students enrolled in a traditional section and an online section of a floral design course.

\begin{tabular}{lcccccc}
\hline $\begin{array}{l}\text { Post-course } \\
\text { statement }^{\mathrm{z}}\end{array}$ & $\begin{array}{c}\text { Students } \\
\text { (no.) }\end{array}$ & Mean $^{\mathrm{y}}$ & SD & $\begin{array}{c}\text { Mean } \\
\text { rank }^{\mathbf{x}}\end{array}$ & Chi-square & $\boldsymbol{P}$ \\
\hline 1 & 56 & 4.34 & 0.436 & 65.19 & 13.256 & $0.010^{*}$ \\
2 & 35 & 4.38 & 0.543 & 70.86 & & \\
3 & 12 & 4.46 & 0.461 & 74.75 & & \\
4 & 3 & 3.96 & 0.115 & 32.67 & & \\
5 & 19 & 3.96 & 0.491 & 39.45 & & \\
\hline
\end{tabular}

${ }^{2}$ Statements were coded as follows: $\mathrm{l}$ = "I was in the traditional course, and I am glad I was (rather than the webbased course)," 2 = "I was in the web-based course, and I am glad I was (rather than the traditional course)," $3=$ "The type of course (traditional or web-based) I was in did not make a difference to me," 4 = "I was in the traditional course, but I really wish I had been in the web-based course," 5 = "I was in the web-based course, but I really wish I had been in the traditional course."

"Means can range from 1 (very unsatisfied) to 5 (very satisfied).

${ }^{x}$ Mean of ranks of data; in a Mann-Whitney test, data are analyzed by ranking the means of the variables of interest.

* Significant at $P<0.05$

scores greater than 4.0 , indicating that overall, students agreed with the positively worded evaluation statements in the instrument. This is consistent with the meta-analysis done by Allen et al. (2002) showing no differences in course satisfaction between traditional and online courses.

No statistically significant differences were reported due to gender, previous experience in an online course, ethnicity, classification, where students accessed the Internet, or their connection speed. However, there were statistically significant differences based on their post-course statement of whether they had been in the sec- tion they wanted (Table 9). Though the non-parametric Kruskal-Wallis test did not pinpoint the differences, the data revealed that in terms of their CEI scores, students who were enrolled in the type of section (online vs. traditional) they preferred (or who did not care which section in which they were enrolled) reported higher evaluation scores for their course when compared to those students who were not enrolled in the type of course they preferred.

Design scores. The other measure of student performance in the course was based on student floral design laboratory skills. Online stu- dents were taught design skills in their laboratory with the use of QuickTime (Apple Computers, Cupertino, Calif.) videos and still image slides, and traditional students were taught design skills by an instructor in a live laboratory. Student designs were evaluated twice during the semester to give first and second design scores. These scores were compared between sections with a Mann-Whitney test (Table 10). In both the first and second design skill scores, statistically significant differences between the two sections were noted, with students in the traditional sections of the course scoring higher on both designs. These results differ from many (Aragon et al., 2002; Buerck et al., 2003; Carey, 2001; Russell, 1999, 2002; Weldon, 1999) that reported equal or better student performance in online courses when compared to traditional courses. Results from both this study and MacAlpine's (2002), indicate that the physical art of floral design may be taught more effectively by traditional live instructors/handson methods vs. online techniques.

Once again, gender tests were run, finding that females outperformed males on both floral laboratory design scores (Table 11). Comparisons based on previous floral design experience, ethnicity, classification, where they accessed the Internet, or their connection speed showed no statistically significant differences. In addition, first design scores were found to be positively correlated with second design scores $(P=$ 0.001 ), indicating that students who started out with better design skills maintained those skills throughout the semester.

\section{Conclusions}

Based on these results, it is recommended that students be screened prior to enrolling in an online floral design course to determine if they

Table 10. A Mann-Whitney U test comparison of students' first and second design scores ${ }^{\mathrm{z}}$ in the study of students enrolled in a traditional section and an online section of a floral design course.

\begin{tabular}{|c|c|c|c|c|c|c|c|c|}
\hline Measure & Sections & $\begin{array}{c}\text { Students } \\
\text { (no.) }\end{array}$ & Mean $^{z}$ & SD & $\begin{array}{l}\text { Mean } \\
\text { rank }^{y}\end{array}$ & $\begin{array}{c}\text { Sum of } \\
\text { ranks }^{x}\end{array}$ & $\mathrm{MWU}^{\mathrm{w}}$ & $P$ \\
\hline First design & Traditional & 44 & 13.36 & 1.20 & 67.57 & 2973.00 & 877.00 & 0.000 * \\
\hline \multirow[t]{2}{*}{ Second design } & Traditional & 46 & 13.15 & 1.75 & 69.24 & 3185.00 & \multirow[t]{2}{*}{886.00} & \multirow[t]{2}{*}{$0.000^{*}$} \\
\hline & Web & 65 & 11.82 & 2.05 & 46.63 & 3031.00 & & \\
\hline
\end{tabular}

${ }^{\mathrm{z}}$ Mean scores range from 5 (poor) to 15 (excellent).

yean of ranks of data; in a Mann-Whitney test, data are analyzed by ranking the means of the variables of interest

${ }^{x}$ Sum of the ranked data (number of cases $\times$ mean rank)

"Mann-Whitney U test statistic.

* Significant at $P<0.05$. 
Table 11. A Mann-Whitney U test comparison of male and female students' first and second design scores ${ }^{z}$ in the study of students enrolled in a traditional section and an online section of a floral design course.

\begin{tabular}{llccccccc}
\hline Measure & Gender & $\begin{array}{c}\text { Students } \\
\text { (no.) }\end{array}$ & Mean $^{\mathbf{z}}$ & SD & $\begin{array}{c}\text { Mean } \\
\text { rank }^{\mathbf{y}}\end{array}$ & $\begin{array}{c}\text { Sum of } \\
\text { ranks }^{\mathbf{x}}\end{array}$ & MWUw $^{\text {w }}$ & \multicolumn{1}{c}{$\boldsymbol{P}$} \\
\hline First design & Male & 28 & 11.93 & 1.86 & 43.29 & 1212.00 & 806.00 & $0.020^{*}$ \\
& Female & 81 & 12.84 & 1.71 & 59.05 & 4783.00 & & \\
Second design & Male & 28 & 11.64 & 2.07 & 43.66 & 1222.50 & 816.50 & $0.017^{*}$ \\
& Female & 83 & 12.61 & 1.97 & 60.16 & 4993.50 & & \\
\hline
\end{tabular}

${ }^{2}$ Mean scores range from 5 (poor) to 15 (excellent).

yean of ranks of data; in a Mann-Whitney test, data are analyzed by ranking the means of the variables of interest.

'Sum of the ranked data (number of cases $\times$ mean rank).

"Mann-Whitney U test statistic.

* Significant at $P<0.05$.

have the characteristics needed to be successful in this type of course. This is in accordance with the Cheurprakobkit et al. (2002) study, where respondents agreed that students should be pre-screened to determine whether they have the skills needed for a web-based class. The screening survey should include the distance learning preparedness survey, the applicable pre-course statement choices, and a question about the student's reasoning for taking the web-based course rather than the traditional offering of the course. This information should be analyzed to determine if a student is "at-risk" for doing poorly in the web-based offering. "At-risk" could be defined as having some combination of the following factors: low distance learning preparedness score, male, statements communicating that the web-based course was not the student's first choice, and statements indicating that the student is taking the web-based offering of the course for the wrong reasons (e.g., avoidance of early morning classes; thoughts that the class is easier).

An in-depth orientation session should also be offered to help acclimate students to the online course environment. Options such as text versions of the audio lectures and community online bulletin boards should also be considered to increase resources available to students. More research is needed to test the gender effects observed. Also, more analysis should be conducted regarding the floral laboratory designs and design scores, to better determine whether a computer can effectively instruct students in the art of floral design.

\section{Literature cited}

Allen, M., J. Bourhis, N. Burrell, and E. Mabry. 2002. Comparing student satisfaction with distance education to traditional classrooms in higher education: A meta-analysis. Amer. J. Distance Educ. 16(2):83-87.

Aragon, S.R., S.D. Johnson, and N. Shaik. 2002. The influence of learning style preferences on student success in online vs. face-to-face environments. Amer. J. Distance Educ. 16(4): 227-244.

Buerck, J.P, T. Malmstrom, and E. Peppers. 2003. Learning environments and learning styles: Non-traditional student enrollment and success in an Internet-based vs. a lecture-based computer science course. Learning Environ. Res. 6:137-155.

Carey, J.M. 2001. Effective student outcomes: A comparison of online and face-to-face delivery modes. DEOSNEWS 11(9). 16 Mar. 2006. <http://www. ed.psu.edu/acsde/deos/deosnews /deosnews11_9.asp>.

Cheurprakobkit, S., D.F. Hale, and J.N. Olsen. 2002. Technicians' perceptions about web-based courses: The University of Texas system experience. Amer. J. Distance Educ. 16(4):245-258.

Field, A. 2000. Discovering statistics using SPSS for Windows. Sage Publ., Thousand Oaks, Calif.

Hong, K. 2002. Relationships between students' and instructional variables with satisfaction and learning from a webbased course. Internet Higher Educ. 5:267-281.

MacAlpine, C.L. 2002. Comparison of digital images and compressed video as supplements in the teaching offloral design. M.S.Agr. Thesis, Dept. of Hort. Sci., Texas A\&M Univ., College Station.

McVay, M. 2000. How to be a successful distance learning student. Pearson Custom Publ., Needham Heights, Mass.
Narey, M.J. 2003. Technology in the fine arts classroom, p. 211-239. In: L.A. Tomei (ed.). Challenges of teaching with technology across the curriculum: Issues and solutions. Info. Sci. Publ., Hershey, Pa.

Nguyen, D. and D. Kira. 2000. Summative and formative evaluations of internetbased teaching, p. 22-38. In: L. Lau (ed.). Distance learning technologies: Issues, trends, and opportunities. Idea Group Publ., Hershey, Pa.

Palloff, R.M. and K. Pratt. 2002. Beyond the looking glass: What faculty and students need to be successful online, p. 171-184. In: K.E. Rudestam and J. SchoenholtzRead (eds.). Handbook of online learning: Innovations in higher education and corporate training. Sage Publ., Thousand Oaks, Calif.

Primary Research Group, Inc. 1997. The survey of distance learning programs in higher education. Primary Res. Group, New York.

Russell, T.L. 1999. The no significant difference phenomenon. North Carolina State Univ., Raleigh.

Russell, T.L. 2002. The "significant difference phenomenon." 16 Mar. 2006. <http://www.nosignificantdifference. org $/>$.

University of South Australia. 2002. Introducing the course evaluation instrument (CEI)/Student evaluation of teaching (SET). 16 Mar. 2006. <http://www. unisanet.unisa.edu.au/sei/evaluation/ceiintro.doc>.

Vonderwell, S. 2003. An examination of asynchronous communication experiences and perspectives of students in an online course: A case study. Internet Higher Educ. 6:77-90.

Weldon, K.L. 1999. Seven trimesters of an online introductory statistics course. 16 Mar. 2006. <http://cade.icaap.org/ voll4.2/weldon.html>.

Willis, B. 1993. Distance education: A practical guide. Educ. Technol. Publ., Englewood Cliffs, N.J. 